
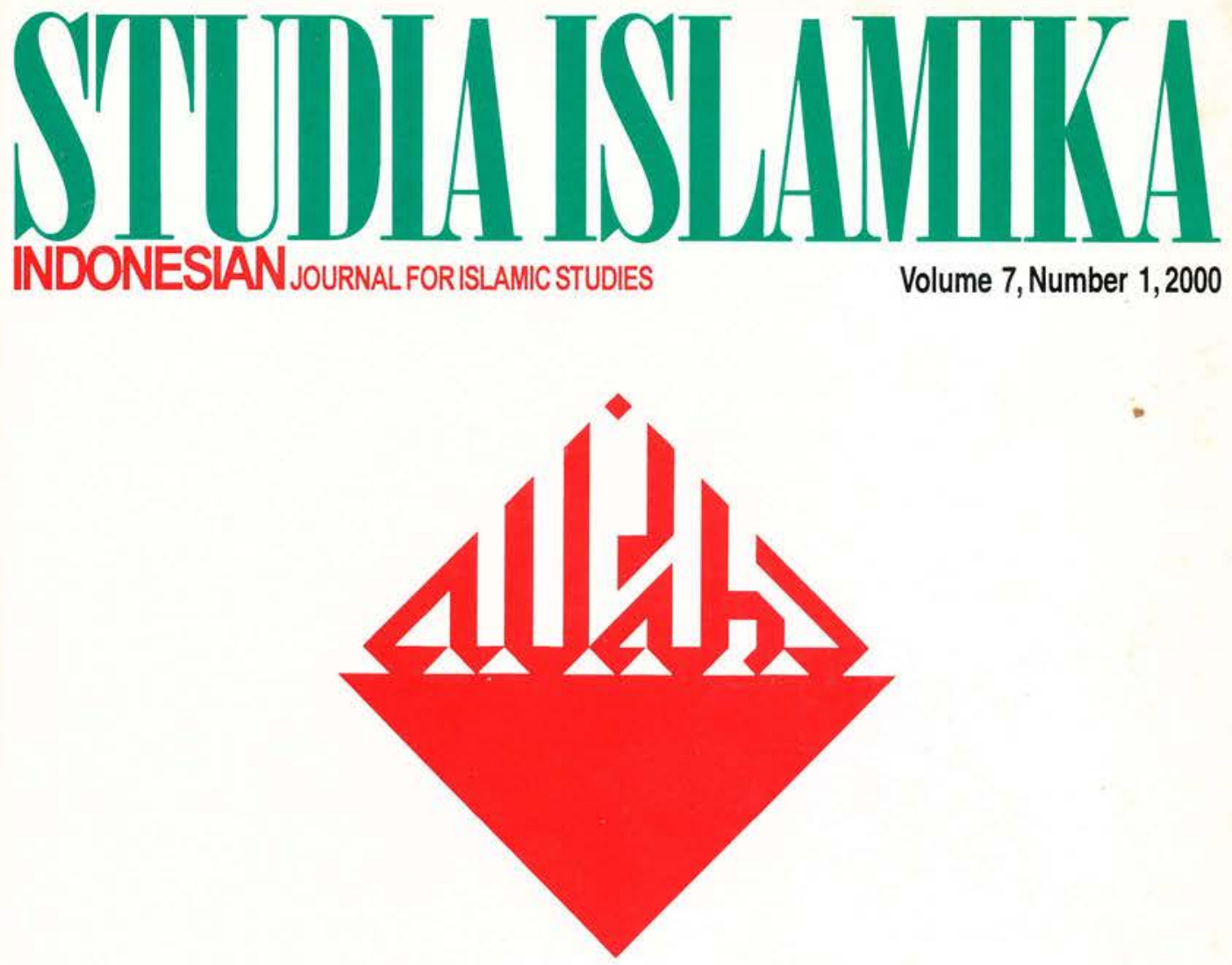

THE ROLE OF IsLAMIC StUdent GROUPS

IN THE REFORMASISTRUGGLE:

KammI (KESATUAN AKSI MAHASISWA MUSLIM INDONESIA)

Richard G. Kraince

IN THE CENTER OF MEANING:

ZIARAHTRADITION IN JAVA

Jamhari

ISLAM AND DUTCH COLONIAL ADMINISTRATION:

THE CASE of PANGULUIN JAVA

Muhamad Hisyam 


\section{STUDDA ISLAVIIKA \\ Indonesian Joumal for Islamic Studies \\ Vol. 7, no. 1, 2000}

EDITORIAL BOARD:

M. Quraish Shihab (IAIN Jakarta)

Taufik Abdullah (LIPI Jakarta)

Nur M. Fadhil Lubis (IAIN Sumatra Utara)

M.C. Ricklefs (Melbourne University)

Martin van Bruinessen (Utrecht University)

John R. Bowen (Washington University, St. Louis)

M. Atho Mudzhar (IAIN Yogyakarta)

M. Kamal Hasan (International Islamic University, Kuala Lumpur)

EDITOR-IN-CHIEF

Azyumardi Azra

EDITORS

Johan H. Meuleman

Jajat Burhanuddin

Fuad Jabali

Oman Fathurahman

\section{ASSISTANT TO THE EDITORS}

Heni Nuroni

ENGLISH LANGUAGE ADVISOR

Richard G. Kraince

Anne Rasmussen

ARABIC LANGUAGE ADVISORS

Nursamad

Amany Lubis

\section{COVER DESIGNER}

S. Prinka

STUDIA ISLAMIKA (ISSN 0215-0492) is a journal published quarterly by the Center for the Study of Islam and Society (PPIM), IAIN Syarif Hidayatullah, Jakarta (STT DEPPEN No. 129/SK/DITIEN/PPG/STT/1976) and sponsored by the Department of Religious Affairs of the Republic of Indonesia. It specializes in Indonesian Islamic studies, and is intended to communicate original researches and current issues on the subject. This journal warmly welcomes contributions from scholars of related disciplines.

All articles published do not necessarily represent the views of the journal, or other institutions to which it is affiliated. They are solely the views of the authors. The articles contained in this journal have been refereed by the Board of Editors.

STUDIA ISLAMIKA has been accredited by The Ministry of National Education, Republic of Indonesia as an academic journal. 


\title{
Pasang Surut Hubungan Agama-agama Jawa
}

\begin{abstract}
Beatty, Andrew, Varieties of Javanese Religion: An Anthropological Account, Cambridge: Cambridge University Press, 1999.
\end{abstract}

Abstract: This book is the most recent publication presenting an antrophological study on the Javanese religion and culture. The seminal work of Clifford Geertz, The Religion of Java (1960), seems to have inspired a number of scholars to study further the complex entities of Javanese reli. gion. The book of Mark Woodward, Islam in Java: Normative Piety and Mysticism in the Sultanate of Yogyakarta (1989), is one of the scholarly works inspired by the division of Javanese religion by Clifford Geertz into abangan, santri and priyayi. The same topic can also be found in the work by Robert Hefner, Hindu Javanese: Tengger Tradition and Islam (1985). However, different from Clifford Geertz who holds the opinion that Javanese religion-albeit plural in its appearance-is basically established on the basis of Hindu-Buddhist, religion the two mentioned scholars state that Islam in an important basis of the Javanese religion.

This book by Andrew Beatty is to provide a new perspective on the discussion over the Javanese religion - how to understand the religious plurality within the Javanese society? In some important aspects, Beatty is influenced by Clifford Geertz, particularly in his explanation on the plurality of religious practices by the Javanese society, ranging from the so-called "the Javanese Cult" to Islam or santri following the term of Geertz. However, again different from Geertz and also from Woodward and Hefner who determine the basis of plurality in Javanese religion-that is Hindu-Buddhist element in the case of Geertz and Islam in the case of Woodward and 
Hefner-Beatty attempts to make a neutral explanation. To Beatty, the significance of Javanese religious plurality lies in the fact that it creates a pattrern of cultural compromise to make an harmonious and stable societal live.

Taking a field study in Banyuwangi, East Java, Beatty finds out the ways the Javanese society handle their problems coming from religious, social and cultural difference, and maintain a harmonious and stable life within the society. The Javanese society of Banyuwangi is of importance for this study. Banyuwangi is geographically far from the centre of Javanese power and culture, Yogyakarta dan Surakarta, and at the same time is distanced from the base area of Islam, Jombang and Tuban. In term of bistory and culture, Banyuwangi has become an area for migration of multietnic communities in Indonesia: Madurese, Chinese, Buginese, Balinese and many other Javanese from central area of Java.

From his study on the Javanese society in Banyuwangi-which is also called as a site of cultural hybrid-Beatty witnesses the way the cultural and religious plurality works and functions as an efective vebicle for making the people socially integrated to build a harmonious life. In this specific point, this work of Beatty presents a criticism againts Fredrick Bath on Balinese religion (Balinese Worlds, 1993). This mode of life is demosntrated by Beatty in his long discussion on slametan, one of the most entrenched rituals in the Javanese society. In this respect, again different from Geertz and Woodward who identified slametan as a ritual belonging to respectively abangan and santri group, Beatty emphasizes the open characteristics of slametan for various construction and meaning by the Javanese society. The slametan is an open ritual laden with various symbols and accordingly social interpretation, even conflicting in nature. Thus if the slametan is practiced in Muslim santri circle it becomes Islamic in colour, likewise if slameten is performed by the abangan people it becomes a local Javanese tradition. It is due to its open characteristics that slametan can efectively function as a medium for integrating various elements of the society.

Understanding the slametan as such then leads Beatty to grasp one other important aspect of the Javanese religion, sincretism. To this aspect, in spite of associating sincretism as a corruption to universal Islamic value, Beatty identifies it as a dynamic process of cultural reproduction, "a systematic relation of various elements of tradition as a response towards cultural plurality and difference". From this understanding of sincretism, Beatty then conceives basic ideas of Javanese religion-such as the concept of god, nature, and buman relationship-in dynamic process of reformulation and reconstruction in accordance with the prevailing social and political condition of the Javanese society. 


\section{Pasang Surut Hubungan Agama-agama Jawa}

Beatty, Andrew, Varieties of Javanese Religion: An Anthropological Account, Cambridge: Cambridge University Press, 1999.

خلاصة: يعرض هذا الكتاب لأحدث الدراسات الأنتروبولوجية حول ديانة جاوه،

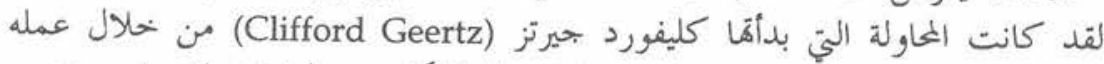

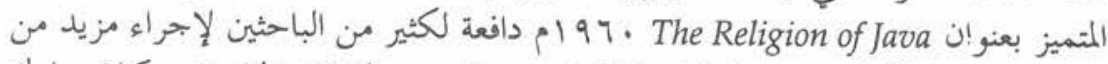

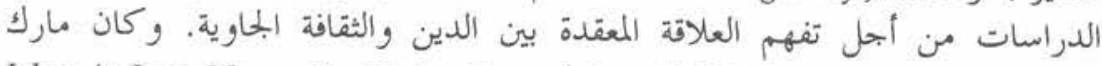

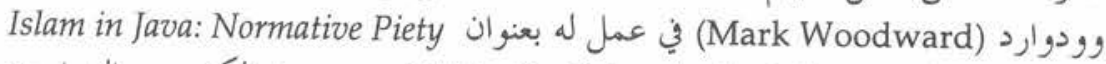
و919 Mysticism in the Sultanate of Yogyakarta

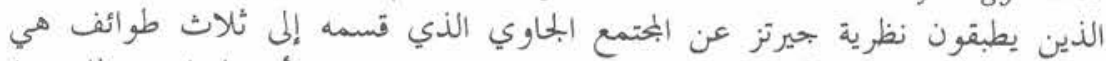

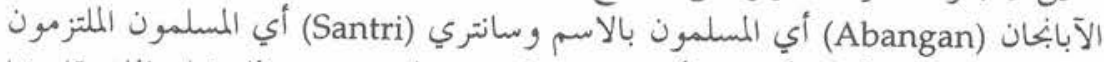

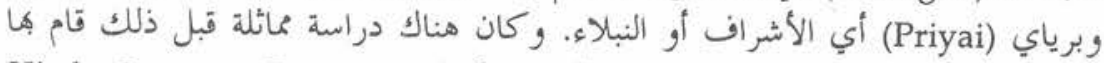

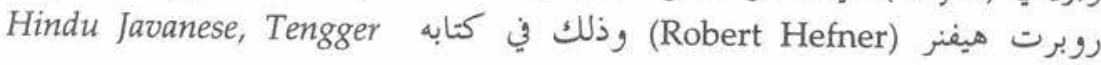

. 1910، Tradition and Islam

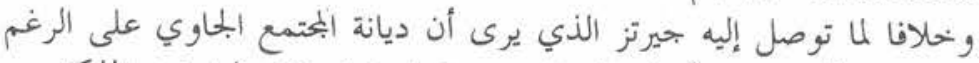

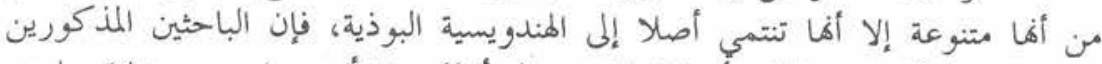

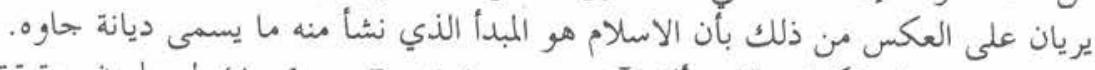

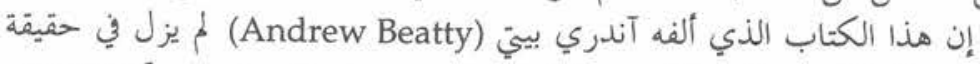

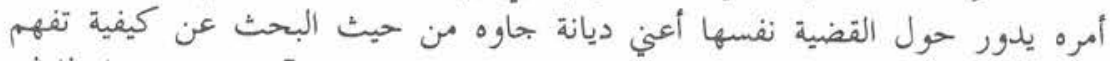

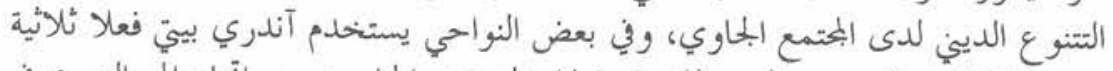

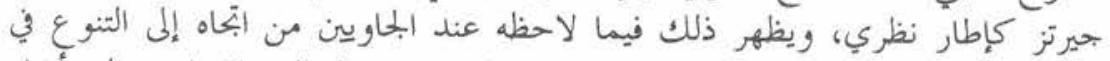

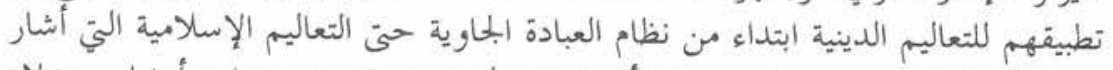

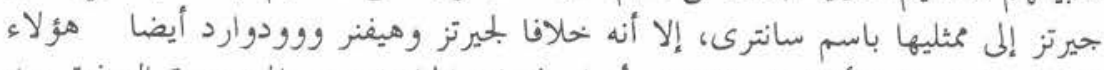

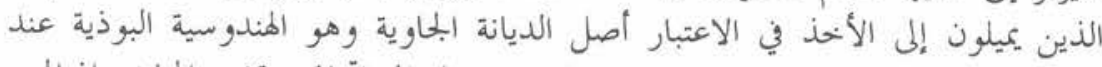

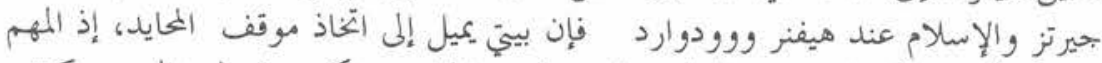

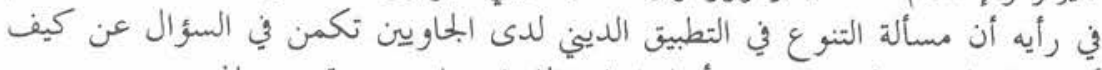

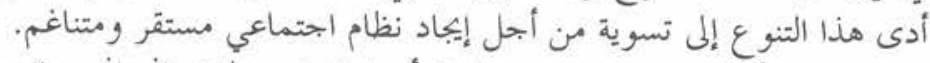

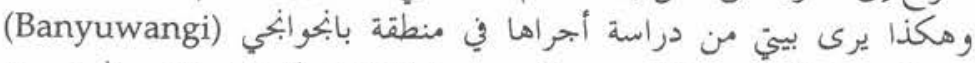

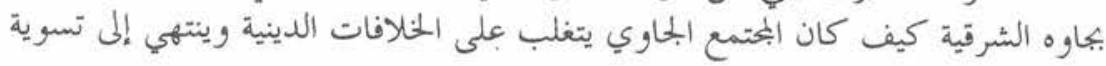


ويحافظ في النهاية على الأوضاع الاجتماعية المستقرة والمتناغمة في الحياة الاجتماعية.

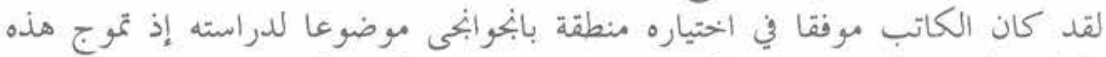

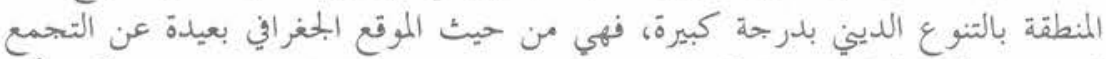

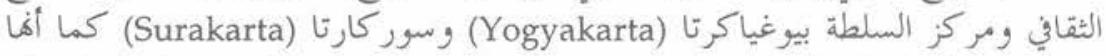

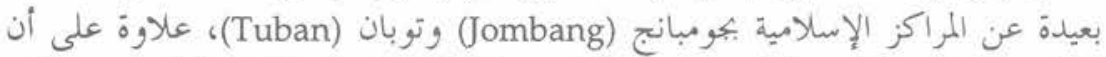

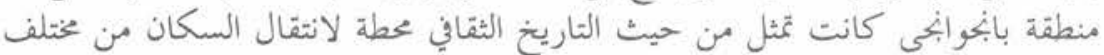

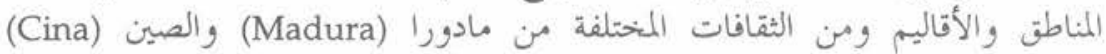

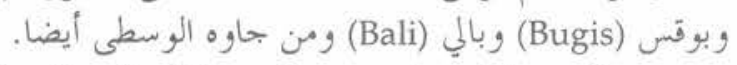

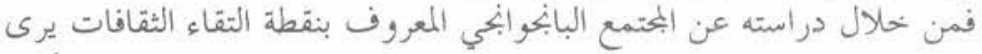

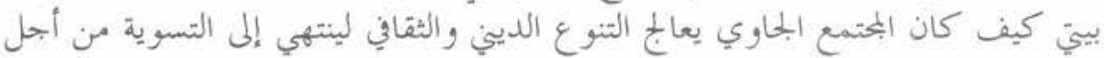

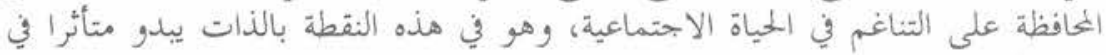

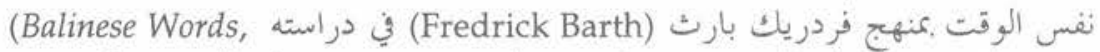

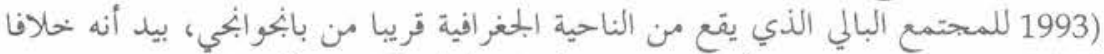

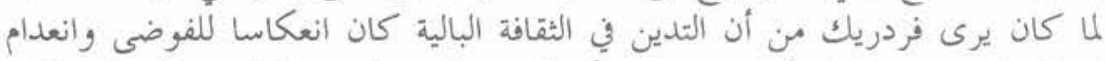

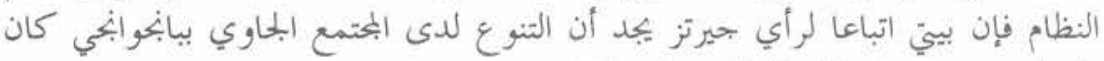

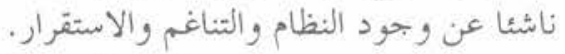

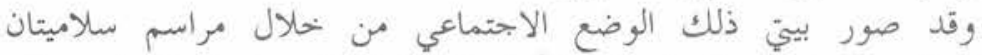

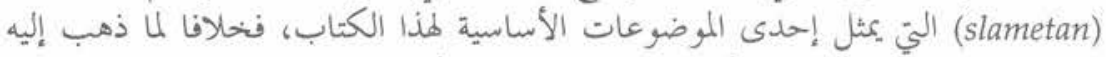

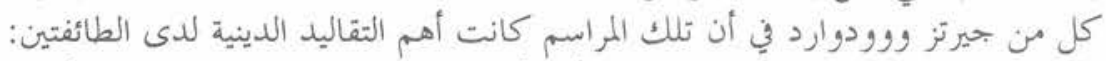

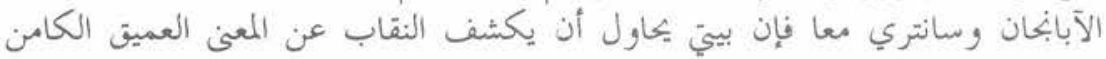

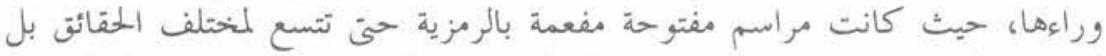

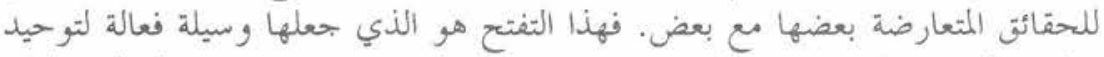

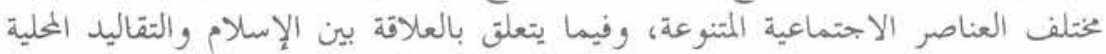

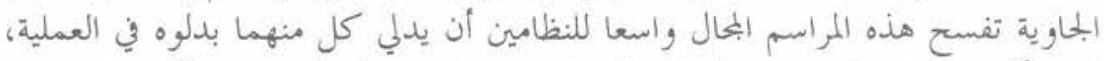

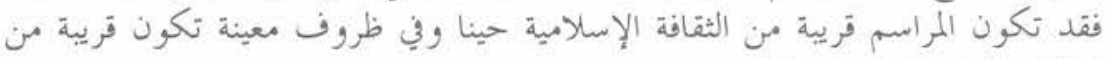

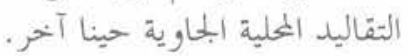

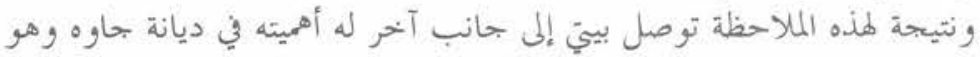

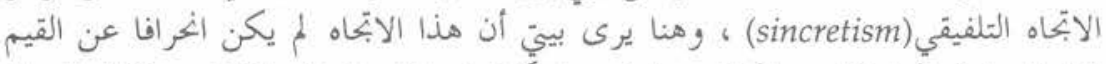

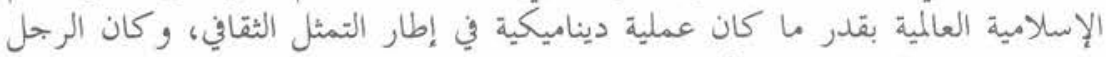

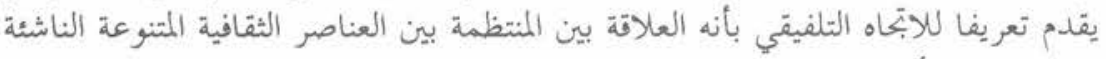

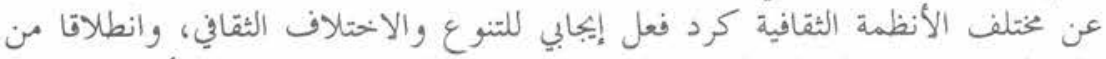

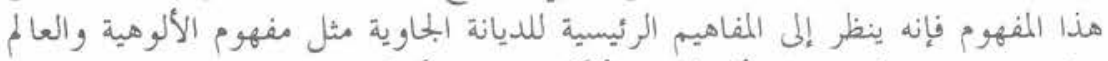

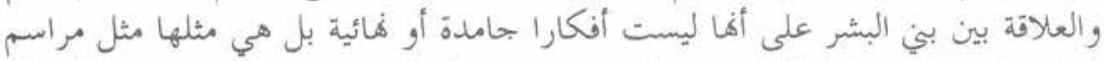

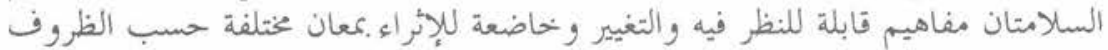

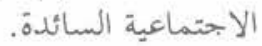


$\mathrm{B}$ uku ini menghadirkan satu kajian antropolog terkini tentang agama-agama di Jawa. Usaha yang dirintis Clifford Geertz be berapa puluh tahun silam tampaknya telah mengilhami banyak sarjana untuk meneliti lebih jauh tentang interaksi agama di Jawa. Karya klasik Geertz, The Religion ofJava, ${ }^{1}$ telah mempopulerkan, bahkan telah membentuk suatu wacana (discourse) tersendiri tentang Islam Jawa. Walaupun sekian banyak karya telah ditulis baik untuk mengkritik maupun mendukung konsep trikotomi-abangan, santri dan priyayi-yang dikembangkan Geertz, ${ }^{2}$ agaknya kritik terbaik untuk Geertz diberikan Mark Woodward, antropolog dari Temple University. Berbeda dengan Geertz yang beranggapan bahwa agama Jawa, meski beragam, pada dasarnya bermuara pada Agama Jawa asli-campuran antara paham animisme dan tradisi Hindu-Budha-Woodward sebaliknya beranggapan justeru Islam yang telah mendasari semua agama Jawa. ${ }^{3}$

Buku yang ditulis oleh Andrew Beatty ini pada dasarnya membahas hal yang sama; bagaimana memaknai keragaman agama di Jawa. Namun berbeda dengan Geertz maupun Woodward, yang tertarik untuk menarik garis dasar dari keberagaman agama Jawa itu-yakni Hindu-Budha untuk kasus Geertz dan Islam untuk kasus WoodwardBeatty lebih tertarik pada bagaimana keberagaman agama Jawa itu menciptakan suatu sistem kompromi untuk membentuk satu tatanan sosial yang stabil dan harmonis.

Oleh karena itu, membaca sepintas judul buku karya Andrew Beatty ini, apalagi jika melihat kover depan bukunya yang memperlihatkan sekelompok orang sedang melakukan slametan, kita mendapat kesan bahwa buku ini mengikuti kerangka pemikiran Clifford Geertz, sekali lagi khususnya tentang slametan. Memang, kesan tersebut tidak sepenuhnya salah. Seperti diakui Beatty sendiri, ia memang banyak diilhami oleh Geertz. Penjelasan Beatty tentang berbagai macam praktek keagamaan di Jawa, dari Javanist Cult sampai dengan Islam, barangkali bisa dikatakan seabagai terilhami oleh tiga varian yang dikembangkan Geertz. Sementara itu penjelasan tentang slametan juga terkesan sama dengan gambaran slametan yang ditulis Geertz.

Namun demikian, mengatakan bahwa Beatty semata-mata mengikuti teorisasi Geertz-menerapkan kerangka teori Geertz untuk melihat masyarakat Jawa kontemporer-juga tidak sepenuhnya benar. Hal ini terlihat dari beberapa kesimpulan Beatty yang berbeda dengan yang diyakini Geertz, misalnya mengenai slametan. Geertz memandang slameten sebagai ritual utama kelompok abangan dan 
karenanya hanya sedikit saja kaum santri melakukannya. Beatty melihat slametan lebih sebagai "cultural compromise" bagi terjadinya toleransi perbedaan pemahaman agama (26). Dalam melihat beragamnya-multivoiced-keyakinan agama di Jawa, Beatty juga berbeda dengan Geertz. Trikotomi-abangan, santri dan priyayi-yang dibuat Geertz mengesankan bahwa masing-masing kelompok tersebut hidup dalam suatu wilayah tersendiri, kemudian terlibat konflik dan tidak berhubungan dengan kelompok lain. Namun dalam kenyataannya, Beatty berargumen, orang Jawa hidup dalam masyarakat yang sangat heterogen, bahkan banyak di antara mereka yang tidak dapat dikelompokkan ke dalam satu tipologi tertentu (115). Oleh karena itu, tipologi yang mengesankan pada pemunculan "sociological category" harus dirumuskan kembali.

Namun demikian, pada saat yang sama, Beatty kurang setuju perumusan kembali tipologi dengan menambahkan kategori-kategori lain atau membuat "grey shadow" pada batas polarisasi seperti yang dilakukan oleh Ricklefs. ${ }^{4}$ Bagaimanapun juga, tipologi-walaupun begitu lengkap - pada dasarnya tidak dapat menjelaskan secara baik kompleksitas dari dinamika interaksi timbal balik agama-agama di Jawa. Walaupun dalam kerangka generalisasi tipologi dapat menjelaskan pluralitas agama Jawa, kompleksitas agama di Jawa tidak hanya terletak pada pluralitas itu sendiri, melain terletak lebih pada saling berhubungannya (interrelation) antar agama dalam dinamika perubahan dan adaptasi dari perbedaan (116). Dan interelasi demikian itu hanya bisa dipahami melalui konteks lokal, bukan melalui satu kategorisasi yang mencerminkan tipe ideal ala Weberian.

Berdasar pada kenyataan itu, Beatty tampaknya terilhami oleh Fredick Barth yang menulis tentang kompleksitas masyarakat Bali. ${ }^{5}$ Di sini, Beatty berusaha melihat bagaimana masyarakat Jawa menyelesaikan perbedaan-perbedaan itu. Selama ini penjelasan mengenai pluralitas agama (religious plurality) di Jawa hanya berhenti pada deskripsi tentang pluralitas itu sendiri, belum menyentuh pada akibat intra-village diversity tersebut terhadap masyarakat maupun hubungan personal dari masing-masing kelompok yang berbeda. Barangkali ada dua kemungkinan yang terjadi, pertama perbedaan itu mungkin akan memunculkan konflik antarkelompok seperti apa yang terjadi pada dekade 1960-an, atau akan menumbuhkan suatu sistem budaya (cultural system) di mana masyarakat mengatur kompromi untuk menjaga kompleksitas itu.

Buku ini, seperti yang tergambar pada awal pengantarnya, hendak 
mengungkapkan tentang "cultural differences and syncretism" dalam masyarakat traditional Jawa sebagai gambaran bagaimana merekamasyarakat tradisional-menyelesaikan masalah perbedaan budaya. Beatty mengatakan bahwa selama ini ide-ide pluralisme selalu merujuk pada kasus-kasus di dunia Barat, padahal masyarakat tradisional seperti Jawa telah melakukan hal itu sejak lama. Bila Barth menemukan bahwa kompleksitas di masyarakat Bali menjadikan gambaran masyarakat Bali yang "kacau, bercabang, dan tidak tetap", Beatty melihat pluralitas di Jawa cerminan suatu masyarakat yang "teratur, harmoni dan tetap." Mengapa demikian, hal itulah yang menjadi kajian utama Beatty dalam buku ini.

\section{Sinkretisme dalam Masyarakat Heterogen}

Secara teoritis Beatty kembali menggunakan konsep sinkretisme yang dipakai Geertz, meski dengan penekanan yang berbeda. Selama ini banyak sarjana yang mengkritik konsep sinkretisme Geertz karena dianggap mengaburkan kenyataan yang sebenarnya. Muhaimin misalnya, dalam disertasinya tentang hubungan agama dan adat di Cirebon, dengan keras menolak konsep sinkretisme Geertz yang dianggap telah menghilangkan makna sesungguhnya hubungan akrab adat dan agama dalam masyarakat Jawa. Sinkretisme juga dianggap sebagai kondisi yang biasa-tidak istimewa-karena hubungan antara agama dan budaya adalah lumrah terjadi dalam proses budaya. Oleh karena itu, pernyataan bahwa Islam di Jawa bersifat sinkretisme adalah tautalogi.

Namun tidak demikian halnya Beatty. Ia menggunakan sinkretisme dalam pengertian yang lebih abstrak, yaitu menunjuk pada "hubungan yang sistematis dari unsur-unsur berbagai macam tradisi sebagai respon yang teratur terhadap pluralisme dan perbedaan budaya" (3). Oleh karena itu, Beatty memakai konsep sinkretisme, meminjam Stewart, lebih sebagai suatu proses yang dinamis dari reproduksi budaya, bukan menekankan hasilnya (3). Dengan demikian dapat dimengerti jika sinkretisme digunakan oleh Beatty karena ia lebih tertarik pada bagaimana menjelaskan keragaman budaya (cultural diversity) dan bagaimana masyarakat mengatasinya untuk menciptakan suatu sistem yang stabil. Proses hubungan antar penganut agama, bagaimana seorang penganut agama tertentu bersikap dan berkompromi dengan kelompok lain, dan bagaimana suatu ritual itu beradaptasi dan berubah sesuai dengan situasi dan kondisi lokal, merupakan bagian penting dari proses interelasi agama dalam suatu 
masyarakat yang heterogen.

Jadi, bagi Beatty, proses interelasi secara historis membuat bentuk sinkretik agama dapat dievalusi dan dikonfigurasi kembali. Kajian sejarah tentu sangat penting untuk mengetahui perbedaan makna dan perubahan kekuasan dalam perubahan waktu. Walaupun begitu, sinkretisme di Jawa tidak begitu saja bisa dijelaskan dengan pendekatan sejarah, karena tidak selamanya hal yang terjadi sekarang ini akibat dari masa lalu (2-4). Namun, hal itu harus ditambah dengan memperhatikan faktor kekinian-seperti posisi Islam, keadaan sosial dan politik serta perubahan kekuasaan negara-yang sangat mempengaruhi proses perubahan pola-pola keberagamaan.

Melihat hubungan antara ritual dan ideologi dalam situasi kultural yang komplek seperti Jawa, selanjutnya membawa Beatty untuk melihat ideologi sebagai suatu idea, bukan sebagai tahapan proses sosial semata. Oleh karena itu sangat perlu diperhatikan bagaimana sebuah ideologi muncul, berubah dan diterima di dalam masyarakat. Beatty berhasil menampilkan, paling tidak memberikan argumen, bagaimana perbedaan itu muncul dari sudut sosial. Beatty juga berhasil memberikan makna terhadap perbedaan-perbedaan ritual dalam kerangka pluralisme yang lebih luas. Keberhasilan Beatty dapat dilihat ketika ia menempatkan ide-ide dasar agama-seperti konsep ketuhanan, alam dan hubungan antar manusia-bukan sebagai konsep semata, tetapi sebuah konsep yang terus diperdebatkan, dikonfigurasi dan dirubah sesuai dengan situasi sosial yang melingkupinya.

\section{Masyarakat Banyuwangi yang Pluralis}

Beatty sengaja mengambil Banyuwangi-sebuah daerah di ujung timur Timur Jawa yang berdekatan dengan Bali-untuk melihat masyarkat Jawa yang jauh dari pusat kekuasaan Jawa (Yogyakarta maupun Surakarta) ataupun pusat-pusat Islam seperti Jombang atau Tuban yang banyak pesantren. Pengambilan Banyuwangi barangkali menunjukkan jelas keterpengaruhan Geertz dan Barth. Dari Geertz Beatty hendak melihat Jawa dari sudut corak dan ragam agamanya, dari Barth ia ingin melihat daerah yang dekat dengan Bali untuk melihat pluralitas di masyarakat tradisional.

Secara budaya, Banyuwangi mempunyai sejarah yang unik. Pertama, Banyuwangi merupakan salah satu daerah yang paling belakangan dijajah oleh Mataran Islam. Walaupun akhirnya Mataram dapat menguasai daerah ini, perlawanan lokal terhadap dominasi Mataram sangat tinggi. Sehingga, bisa dikatakan bahwa Banyuwangi, 
meski mempunyai kesamaan dengan wilayah pedalaman Jawa, memperlihatkan corak tersendiri. Kekhususan Banyuwangi tersebut ditambah dengan kedekatannya dengan Bali yang didominasi Hindu Bali. Kerajaan-kerajaan Hindu Bali, meski gagal, pernah beberapa kali mencoba memasuki wilayah Banyuwangi. Dengan demikian, pengaruh Hindu Bali di Banyuwangi, walaupun tidak besar, cukup signifikan. Keberadaan agama Hindu yang cukup dominan di Banyuwangi disebabkan juga karena wilayah ini, selain Bali, menjadi pelarian orang Majapahit ketika ditaklukkan oleh Kerajaan Islam.

Oleh karena itu, sejarah Banyuwangi diwarnai oleh posisi yang kurang beruntung (unfortunate position) dalam peta kekuasaan Jawa; di satu sisi menjadi wilayah pinggiran Jawa, dan di sisi lain menjadi wilayah luar dari Hindu Bali. Budaya kontemporer Banyuwangi mencerminkan cangkokan dari budaya-budaya (cultural hybrid) tersebut; bahasa mereka diwarnai oleh Bahasa Jawa Kuno yang diperkaya dengan pinjaman Bahasa Bali; Seni traditional mereka memakai Bahasa Krama Jawa tetapi tarian mereka dipengaruhi oleh tarian Bali; dalam masalah agama mereka sangat variatif (polyphonic) yang berakar pada kepercayan Jawa Kuno tetapi disemaikan dalam ritus formal Islam.

Penduduk Asli Banyuwangi, tidak seperti daerah Jawa lain, disebut sebagai Osing atau Wong Jawa Osing. Tidak jelas kenapa mereka disebut demikian. Satu spekulasi menjelaskan bahwa kata osing kemungkinan disebabkan karena bahasa lokal untuk menyebut tidak adalah osing. Sehingga ketika imigran Jawa datang ke daerah Banyuwangi, mereka menyebut penduduk asli sebagai "ora Jawa" kemudian dikenal sebagai Osing Jawa.

Keragaman tersebut selanjutnya juga disebabkan proses migrasi masyarakat sekitar Banyuwangi. Setelah Belanda menaklukkan Banyuwangi dengan menelan korban yang begitu besar-ada yang memperkirakan bahwa sekitar 60.000 orang meninggal dalam peperangan itu-Belanda menganjurkan orang Jawa dari daerah sekitarnya untuk menempati Banyuwangi karena kekurangan penduduk. Sejak itu orang Cina dari Batavia juga didatangkan, orang Madura yang daerahnya kurang subur juga pindah ke Banyuwangi, bahkan sampai pelacur-pelacur dari Semarangpun didatangkan ke Banyuwangi (16-17). Maka Banyuwangi terkenal sebagai daerah buangan. Belanda menempatkan para migran yang berasal dari berbagai suku itu ke dalam satu wilayah tertentu. Misalnya orang Madura ditempatkan didaerah utara dan dipekerjakan dalam perkebunan. Sementara itu 
orang nelayan Madura dan Bugis serta pedagang Cina dan Arab ditempatkan di pusat kota dan menjadi model bagi ekonomi plural. Juga ikut menempati Banyuwangi adalah orang Jawa Tengah, yang orang lokal Banyuwangi menyebut mereka sebagai wang kulonan, atau wang Mentaram.

Keunikan posisi Banyuwangi ini berakibat pada beragamnya corak keberagaman masyarakat. Di satu fihak, keadaan Banyuwangi tidak bisa terlepas dari proses Islamisasi yang mendominasi Jawa sejak abad ke-13, bahkan sampai sekarang ini. Namun di lain pihak, Banyuwangi juga memberikan indikasi bahwa proses islamisasi di Jawa tidaklah seragam dengan hasil yang sama (16). Keberadaan masyarakat lokal Banyuwangi yang masih percaya pada kultus Jawa (Javanist cult) memberi corak tersendiri bagaimana antarkelompok berbeda ritual berinteraksi. Belum lagi keberadaan Hindu dan Aliran kebatinan (Javanist Philosophy) hidup berkembang baik di wilayah ini. Semua ini menjadi gambaran keragamaan masyarakat Banyuwangi, jika tidak bisa dikatakan unik, yang berbeda dengan keadaan masyarakat Jawa pada umumnya.

\section{Keragaman Agama Jawa}

Islam tampak mendominasi pedasaan Banyuwangi, terbukti dengan dipakainya modin dalam berbagai upacara keagamaan-pejabat kelurahan yang bertugas mengurusi agama Islam seperti dalam pernikahan, kematian dan memberikan do'a dalam setiap kesempatan upacara keagamaan. Diterimanya Islam di banyak wilayah pedesaan menunjukkan popularitas Islam di wilayah ini. Namun begitu di wilayah pedalaman terdapat kelompok masyarakat yang terdiri dari serdadu pejuang (warior) yang masih loyal kepada kekuasaan lama (old religious order). Di tempat lain juga ditemukan kantong-kantong wilayah yang penduduknya masih menganut agama Hindu-Buda yang hidup hingga abad ke-19. Bahkan ketika Van der Tuuk (1923), yang mengunjungi Banyuwangi pada tahun 1840, masih menemukan sekelompok masyarakat yang mempraktekkan Swa Buddha, padahal telah 3 abad Majapahit ditaklukkan Islam. Dalam enam dari sembilan bab Beatty memaparkan keberagaman agama di Jawa.

Bab 3 berisi tentang faham kultus Jawa, terutama kultus pada pendiri desa yang direpresentasikan dalam slametan atau pertunjukan $\mathrm{Ba}$ rong yang menggambarkan aspek mistik dari pudhen Ki Buyut. Slametan yang diadakan di makam pundhen desa, makam Ki Buyut, ternyata tidak dilakukan oleh orang-orang yang menganut paham kultus Jawa 
saja. Orang Islam pun mengadakan slametan di tempat tersebut. Interpretasi dari slametan yang diadakanpun tergantung latar belakang paham keagamaan partisipannya. Seperti halnya ziarah ke makammakam suci, slametan yang diadakan di kramat desa juga dimaksudkan untuk mencari berkah duniawi.

Pertunjukan Barong, berbeda dengan pertunjukan serupa di Bali, adalah pertunjukan semalam. Seperti halnya wayang, walaupun cerita keseluruhannya dapat dilihat, pertunjukan Barong dibagi ke dalam beberapa penggalan. Sering orang melihat Barong pada bagian-bagian yang disukai saja. Bagian terpenting dari pertunjukan Barong tersebut adalah bagian akhirnya yang menunjukkan ketika pemain $\mathrm{Ba}$ rong kemasukan roh macan Ki Buyut. Roh tersebut hanya dapat dikeluarkan oleh Juru Kunci dari makam keramat Ki Buyut.

Meskipun dua ritual tersebut-melakukan slametan di makam pundhen dan pertunjukan Barong-dapat dikatakan berasal dari paham keagamaan non-Islam, kenyataannya orang yang melakukan slametan dan yang menonton pertunjukan Barong tidak saja terdiri dari kelomnpok tertentu saja. Akibatnya makna dan bentuk ritual dari kedua hal tersebut sangat dipengaruhi oleh lingkungan sosial termasuk di dalamnya adalah pengaruh Islam. Misalnya dalam slametan. Interpretasi tentang makna slametan berbeda: misalnya slametan atau berkunjung ke makam diartikan sebagai kunjungan penghormatan semata, tidak meminta bantuan dari Ki buyut untuk meminta barakah.

Keragaman agama Jawa juga tercermin dalam varian lain yang Beatty kelompokkan ke dalam Practical Islam. Beatty ingin menghindari kesalahan-kesalahan peneliti sebelumnya yang menjelaskan Islam dalam kerangka Islam modernis maupun Islam traditionalis. Terlepas dari kedua macam pandangan tersebut, Beatty menjelaskan Islam menurut apa yang dipraktekan orang (Islam as practiced by people). Dengan demikian Beatty tidak begitu memperhatikan detail argumentasi dari pengamalan agama di masyarakat. Memang dalam kenyataannya ahli agama Islam, seperti yang direpresentasikan diantaranya oleh modin, menjadi juru bicara bagi rakyat biasa, dan oleh karena itu apa yang dipraktekkan orang banyak mencerminkan apa yang diyakini oleh ahli agamanya. Beatty menemukan bahwa seorang yang dikenal saleh, artinya taat mengerjakan agama dan mengerti argumentasi dari ajaran Islam, sering juga mengerjakan dan mempercayai sesuatu yang diluar ajaran Islam, seperti seorang Modin yang percaya pada paham reinkarnasi bagi manusia yang sudah mati (155). 
Oleh karena itu, agak sukar untuk membuat simplifikasi terhadap praktek Islam di masyarakat Banyuwangi, walaupun dapat dengan mudah diterka bahwa pengaruh Islam traditional sangat kuat di daerah ini sebagaimana daerah Jawa Timur pada umumnya. Namun yang jelas bahwa pemahaman dan sekaligus praktek keislaman yang berkembang di masyarakat sangat bervariasi-ada yang longgar melaksanakan agama, ada yang fanatik, ada yang giat menjadi penyiar agama, konservatif dan bahkan yang skeptis (156). Di samping perbedaan itu, ada satu usaha untuk menemukan satu bahasa yang dapat mengatasi perbedaan, yakni "kemauan mereka membuat konsensus untuk menjaga harmoni sosial dalam hidup bertetangga” (156). Hubungan yang muncul tidaklah membuat blok dan kelas tersendiri, melainkan adanya usaha untuk saling tukar menukar, mengadakan dialog dan membuat kompromi, dengan kata lain menciptakan batas yang samar (a blurring boundaries).

Dari dua contoh yang menggambarkan corak ragam agama Jawa, Beatty beranggapan bahwa, apapun medianya dan bagaimanapun ritualnya, masyarakat Jawa telah membuat suatu wacana kompromi untuk menjamin terwadahinya perbedaan demi kerukunan sosial. Bagaimana kompromi tersebut dapat diciptakan, Beatty mengambil contoh slametan sebagai common ground dari perbedaan keagamaan di Jawa.

\section{Slametan sebagai Medium Kompromi Sosial}

Banyak sarjana yang mengkritik Geertz ketika dia mengemukakan pentingnya posisi slametan sebagai corak utama ritual kaum abangan yang didominasi oleh petani Jawa. Kritik tersebut terutama datang dari Mark Woodward yang mengatakan bahwa ide slametan adalah bersumber dari teks Islam. Lebih jauh dia mengatakan "slametan adalah produk dari interpretasi teks Islam dan bentuk aksi ritual yang dihargai masyarakat luas Muslim" (1989:62). Dia juga berpendapat bahwa slametan adalah model yang diambil dari ritual yang diselenggarakan kraton Jawa yang diilhami ajaran Sufi. Di samping Woodward, Muhaimin juga berargumentasi bahwa slametan berasal dari Islam, melihat kata slametan sendiri berasal dari bahasa Arab yang akar bahasanya sama dengan akar bahasa Islam (sa-la-ma).

Terdapat dua hal penting yang dilihat oleh Beatty mengenai slametan. Pertama, interpretasi tentang dedikasi kepada siapa slametan diberikan, dan kedua interpretasi makanan yang disajikan dalam slametan. Kompleksitas makna slametan mencerminkan pentingnya posisi 
slametan dalam agama Jawa. Beatty melihat bahwa slametan adalah penting untuk melihat "sifat dari sinkretisme sebagai proses sosial, hubungan antara Islam dan tradisi, dan lebih penting dari itu melihat multi dimensi simbol yang terkandung di dalam slametan" (26). Beatty melihat slametan sebagai "pattern of cultural compromise" di mana perbedaan interpretasi dan pelaksanaannya ditolerir dan diberi ruang untuk bereksperimen.

Dalam memberikan makna pada makanan yang disajikan misalnya, jenang abang dan jenang putih sebagai representasi dari kebaikan dan keburukan. Sementara yang lain mengartikan jenang putih sebagai lambang roh dan jenang abang sebagai lambang darah. Perbedaan pemahaman juga bisa ditemukan lewat kirata basa, arti dari penggalan kata yang dipakai. Misalnya saja, orang Muslim modernis di Yogya mengartikan apem sebagai kata yang diambil dari bahasa Arab, 'afwun yang berarti maaf, sementara yang lain mengartikan apem sebagai sepadanan kata marem.

Sebagai ritual yang penuh simbol, maka slametan adalah sebuah simbul terbuka yang mempunyai aspek polysemic-beberapa makna, dan juga terkadang saling bertentangan (conflicting interpretation). Keterbukaan tersebut selanjutnya menjadikan slametan sebagai medium untuk menyatukan beberapa masukan dari berbagai unsur dalam praktek ritual. Dalam hubungan antara Islam dan tradisi lokal Jawa, sifat polysemic slametan memberikan ruang lebar untuk kedua budaya tersebut mewarnai ritual slametan; pada suatu waktu bisa lebih dekat kepada Islam dan pada kondisi sosial lain dapat lebih dekat interpretasinya kepada tradisi lokal Jawa. Dengan demikian, kebenaran interpretasi dari makna simbol dapat dikatakan sebagai kebenaran relatif. Keterbukaan makna slametan juga memberikan gambaran bahwa tidak ada nilai yang dominan secara terus menerus dalam slametan.

Karakteristik demikian itulah yang membuat posisi slametan dalam agama Jawa begitu penting. Slametan-karena semua partisipan terlibat dan semua kelompok masyarakat melakukannya-dapat mentrasendenkan perbedaan dengan nilai dasar Jawa yang sama. Lebih dari itu, slametan menyatukan mereka, sebagai laki-laki dan perempuan, bukan sebagai Muslim dan Hindu atau yang lainnya. Kemudian kemudahan slametan beradaptasi dengan budaya lain, menyebabkan akomodasi antara Islam dan tradisi lokal Jawa berjalan fluaktif sesuai dengan interpretasi personal partisipannya. 


\section{Beberapa Catatan Apresiatif dan Kritis}

Buku ini, seperti halnya pujian Hefner yang dikutip di kover belakang buku, merupakan karya yang apik. Tidak saja Beatty mampu memberikan gambaran yang lengkap tentang variasi agama Jawa, ia juga memberikan data etnografi yang kaya dan mendalam. Bahkan Hefner mencatat karya Beatty ini sebagai yang terbaik - tentu setelah Geertz-tentang multi-voiced agama di Jawa. Buku ini juga mampu memberikan gambaran tentang kompleksitas dari hubungan antaragama di Jawa, serta bagaimana masyarakat traditional membentuk suatu sistem kompromi budaya (a system of cultural compromise) untuk mewujudkan harmoni sosial. Beatty menemukan bahwa cultural compromise dibentuk dengan memberikan ambivalensi terhadap interpretasi makna dari ritual simbol. Di samping itu, flexibilitas mengadapsi tradisi dari luar memberikan sikap toleran dan fleksibel untuk berubah dalam memahami agama dan menjalankan ritual keagamaan.

Namun begitu, Beatty agaknya terlalu yakin pada sistem sosial yang dapat mengatur dirinya sendiri. Ia tidak begitu memberi perhatian pada aspek eksternal soso-cultural suatu masyarakat yang dapat mempengaruhi keagamaan mereka. Apa yang ditunjukkan Hefner, bahwa perubahan agama Hindu Tengger banyak dipengaruhi proses Islamisasi yang pesat di Jawa, tampaknya penting diperhatikan. Oleh karena itu, pemihakan keberagamaan dan kecenderungan memihak kepada interpretasi tertentu, kadang-kadang tidak lahir dari dalam diri penganut agama. Kondisi sosial terkadang memaksa orang untuk mengikuti bentuk ritual tertentu. Jadi, volunter religion di Jawa mungkin tidak sepenuhnya benar.

Hefner misalnya menunjukkan bahwa konflik agama di Pasuruan, daerah yang tidak jauh dari Banyuwangi, menjelang dan setelah pemilu multi partai tahun 1955, sangat dipengaruhi oleh dua faktor: faktor penguasaan sektor ekonomi dan faktor ideologi dan agama. Hefner juga menunjukkan bahwa pola imigran yang mengelompok dan mempunyai perilaku ekonomi sendiri, ternyata juga menumbuhkan konflik. Walaupun Beatty juga menyebut pola migrasi dan pengelompkan etnis di Banyuwangi, ia tidak memandang hal itu suatu prasarat konflik di masyarakat.

Jadi, tidak adanya konflik antar agama bisa jadi bukan akibat dari adanya sistem kompromi di Jawa, tetapi mungkin lebih disebabkan karena begitu kuatnya hegemoni rezim Orde Baru dengan militer sebagai pendukungnya, yang membungkam segala bentuk pemunculan identitas kelompok tertentu. Sikap yang demikian itu justru 
menumpuk masalah dan memunculkan bara konflik yang bahaya. Terbukti setelah jatuhnya Orde Baru dan mengendurnya peran sosial politik militer, konflik yang berbau agama dan etnisitas bermunculan.

Barangkali Beatty akan mempunyai pandangan yang berbeda seandainya penelitiannya dilakukan setelah terjadinya tragedi Banyuwangi 1998, di mana banyak dukun santet dan kyai serta guru ngaji yang menjadi korban pembunuhan. Mungkin Beatty akan mengatakan bahwa hal itu terjadi karena salah satu agama telah memaksakan pemahaman tertentu kepada yang lain sehingga menimbulkan konflik. Namun, penjelasan itu agaknya tidak memadai, karena susah untuk mendefinisikan siapa yang memaksakan kehendak. Penjelasan itu juga tidak cukup karena terbukti bahwa kasus yang terjadi di Banyuwangi tidak terlepas dari konstelasi sosial politik Indonesia. $\mathrm{Hal}$ ini menunjukkan bahwa sistem kompromi lokal tidak kebal dari pengaruh dari luar. Dalam konteks inilah apa yang dikatakan Kim Hung Jung, seorang antropolog Korea lulusan the Australian national University penting dicatat. Dia mengatakan bahwa seandainya ia memilih desa penelitiannya yang dekat dengan faham kejawen, ia akan mempunyai pandangan berbeda dengan penelitian yang ia lakukan di desa yang didominasi Muslim modernis di Yogyakarta (1996).

Terakhir, misteri tentang agama di Jawa nampaknya akan terus menjadi kajian menarik. Buku ini salah satu yang memperkaya khazanah studi tentang agama di Jawa. Akan banyak lagi studi-studi yang muncul, mengingat tidak ada satu penjelasanpun yang dapat memberi gambaran rinci tentang suatu masyarakat yang komplek dan kaya akan budaya seperti Jawa. 


\section{Catatan}

1. Clifford Geertz, The Religion of Java, (Glencoe: The Free Press, 1960). Dalam wawancaranya yang dimuat di majalah Cultural Anthropology, Geertz mengungkapkan bahwa pada mulanya ia tak setuju dengan judul buku tersebut, karena tidak sepenuhnya cocok dengan bahasan di dalamnya. Namun penerbit beralasan bahwa judul The Religion of Java akan lebih menarik, dan lebih penting dari itu karya Geertz tersebut meneruskan cita-cita Weber yang menulis agama dalam berbagai masyarakat.

2. Beberapa karya berikut ini ditulis sebagai respon-baik mengkritik maupun mendukung-terhadap karya klasik Clifford Geertz, yakni Harsa Bahtiar, "The Religion of Java: a Commentary", Majalah Ilmu-Ilmu Sastra Indonesia, 5, 1973, hal. 85-110; Zaini Muchtarom, Santri dan Abangan di Jarwa, Jakarta: INIS, 1988); Hefner, "Islamizing Java? Religion and Politics in Rural East Java", Journal of Asian Studies, 46, 3, 1987, hal. 533-555; Talal Asad, "Anthropological Conceptions of Religion: Reflection on Geertz", Man (NS), 18, 1983, hal. 237-259; William R. Roff, "Islam Obscured? Some Reflection on Studisn on Islam and Society in Southeast Asia", Archipel, 29, 1985, hal. 7-34; John R. Bowen, "Western Studies of Southeast Asian Islam: Problem of Theory and Practice", Studia Islamika, Vol. II, No. 4, 1955; Lihat pula Muhaimin A.G., "The Islamic Tradition of Cirebon: Ibadat and Adat among Javanese Muslims" Ph.D. Thesis, Canberra: The Australian National University, 1995.

3. Lihat Mark R. Woodward, Islam in Java: Normative Piety and Mysticism in the Sultanate of Yogyakarta, (Tucson: University of Arizona Press, 1989).

4. Lihat karyanya, "Six Centuries of Islamization in Java", dalam Nehemia Levtzion (ed.), Conversion to Islam, ( New York: Holmes and Meir, 1979).

5. Fredrick Barth, Balinese Worlds, (Chicago: Chicago University Press, 1993).

Jamhari adalah staf pengajar pada Fakultas Dakwah, IAIN Syarif Hidayatullah, Jakarta; memperoleh gelar $\mathrm{PhD}$ dalam bidang Antropologi dari The Australian National University (ANU), Canberra. 